This item was submitted to Loughborough's Institutional Repository (https://dspace.lboro.ac.uk/) by the author and is made available under the following Creative Commons Licence conditions.

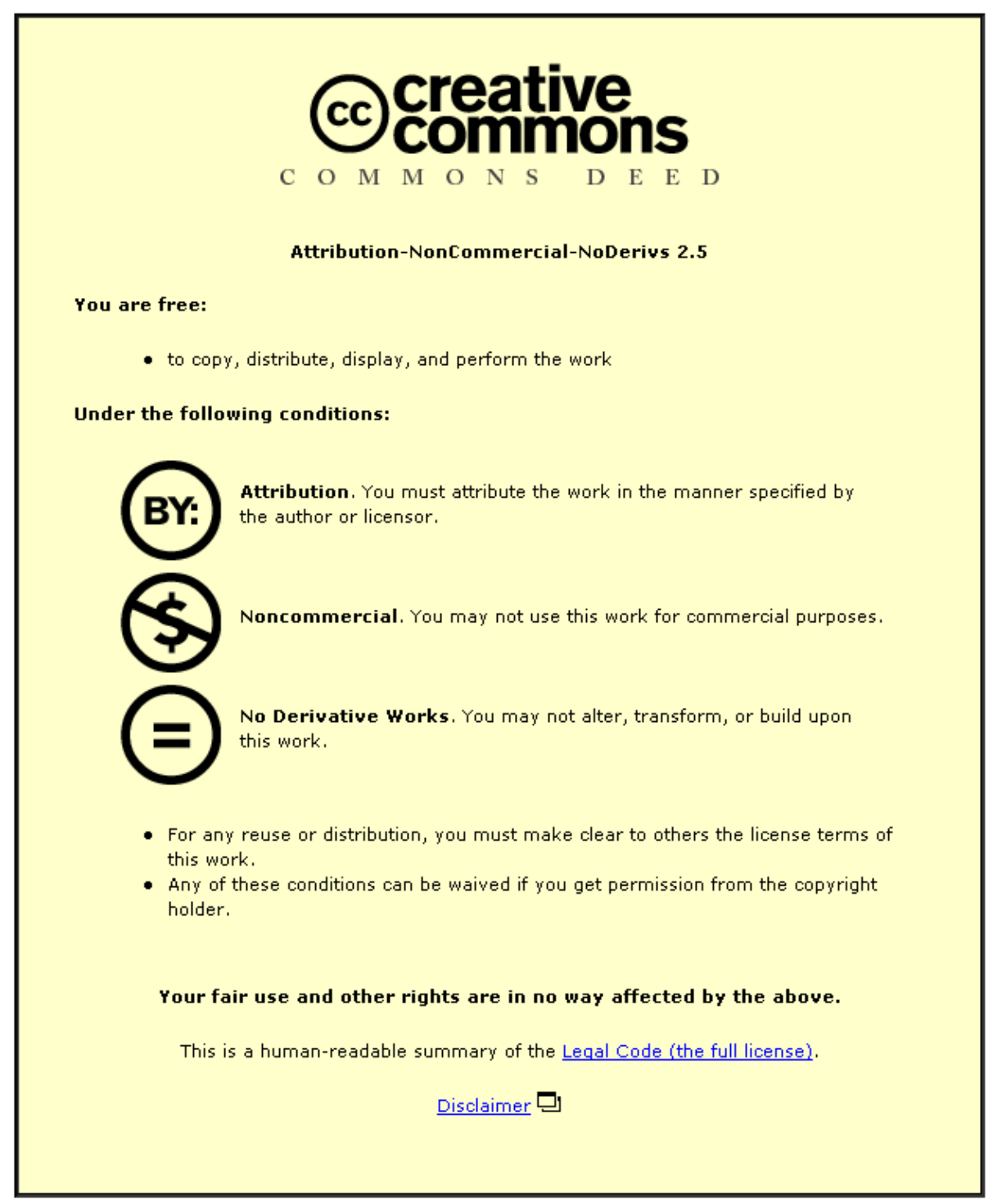

For the full text of this licence, please go to: http://creativecommons.org/licenses/by-nc-nd/2.5/ 


\title{
Characterisation of stearate/stearic acid coated fillers
}

\author{
M. Gilbert, P. Petiraksakul, and I. Mathieson
}

Selected magnesium hydroxide and calcium carbonate fillers were dry coated with stearic acid and calcium, magnesium, and zinc stearates. The course of the coating reaction was monitored using a quantitative diffuse reflectance Fourier transform infrared spectroscopy method and by thermal analysis. The coated fillers were also examined by wide angle $X$-ray diffraction and by $X$-ray photoelectron spectroscopy. These techniques were shown to produce complementary information. When the dry coating process was useded, complex reactions occurred. Stearic acid reacted to produce stearate, while the stearates melted and formed coatings, but in some cases they also appeared to form polymorphic metal stearates. Stearic acid produced the best coverage on calcium carbonate, but the poorest on magnesium hydroxide. Of the metal stearates, the best filler coverage was produced when zinc stearate was used, while calcium stearate was the least effective coating.

MST/4956

At the time this work was carried out the authors were in the Institute of Polymer Technology and Materials Engineering, Loughborough University, Loughborough, Leicestershire LE11 3TU, UK (M.Gilbert@lboro.ac.uk). Dr Petiraksakul is now in the Department of Material Technology, Ramkhamhaeng University, Bangkok 10240, Thailand. Manuscript received 8 January 2001; accepted 2 May 2001.

(C) 2001 IoM Communications Ltd.

\section{Introduction}

Fillers are increasingly used in thermoplastics, either to reduce costs or, more frequently, to enhance properties such as modulus, tensile strength, and heat distortion temperature. ${ }^{1}$ In some cases, however, the incorporation of fillers leads to a reduction in some mechanical properties, particularly toughness. Filler coatings can be used to modify filler surfaces, ${ }^{2}$ and can increase impact strength and facilitate processing, while stiffness improvements are maintained. In many cases, it is found that coatings function by enhancing filler dispersion. ${ }^{3}$ One of the most widely used coatings is stearic acid. ${ }^{1,2}$ Recent work carried out by Hornsby and Watson ${ }^{4}$ showed that metal stearates were particularly effective as coatings for reactive particulate fillers, such as magnesium hydroxide, producing polypropylene compounds with better impact resistance than those containing uncoated, or stearic acid coated fillers. Recent work has identified the optimum coating levels of stearates and stearic acid on selected grades of magnesium hydroxide and calcium carbonate in polyethylene compounds. ${ }^{3,5,6}$ In the work reported here, based on a recent presentation, ${ }^{7}$ these same grades have been coated with equivalent levels of calcium, magnesium, and zinc stearates and stearic acid. The properties of compounds produced using the coated fillers were found to vary with stearate type, for example a calcium stearate coating produced the best impact properties for magnesium hydroxide filled compounds. ${ }^{6}$ The coating process was therefore characterised using a variety of techniques, in an attempt to understand the observed differences.

\section{Preparation and of coated fillers}

\section{MATERIALS}

The fillers used were magnesium hydroxide DP393, supplied by Premier Periclase $\left(13 \mathrm{~m}^{2} \mathrm{~g}^{-1}\right.$ surface area and $0.8 \mu \mathrm{m}$ average particle size) and an experimental grade of calcium carbonate, supplied by ECC $\left(17.33 \mathrm{~m}^{2} \mathrm{~g}^{-1}\right.$ surface area and $0.55 \mu \mathrm{m}$ average particle size). Details of the coating agents are given in Table 1 . The calcium stearate was provided by Harochem Chemicals and the remainder of the coatings were obtained from Fisons. The differences between the melting temperatures obtained by differential scanning calorimetry (DSC), and those in the literature are discussed elsewhere in this paper.

\section{SPECIMEN PREPARATION}

The fillers were dry coated using two types of equipment. In order to establish optimum coating conditions $80 \mathrm{~g}$ specimens were coated using a $1 \mathrm{~L}$ Waring blender. The temperature inside this blender was controlled by altering the voltage across a heating coil; the temperature was recorded every $2 \mathrm{~min}$ and the specimens were removed for Fourier transform infrared spectroscopy (FTIR) analysis as required. Larger specimens, for subsequent incorporation into polyethylene to produce compounds, were prepared using an $8 \mathrm{~L}$ Fielder high speed mixer. Before mixing, the filler was dried for at least $12 \mathrm{~h}$ at $60^{\circ} \mathrm{C}$. The filler was preheated in the Fielder for 5 min using a rotor speed of $1000 \mathrm{rev} \mathrm{min}^{-1}$ and a set temperature of $140^{\circ} \mathrm{C}$. The coating was added when the filler reached $60^{\circ} \mathrm{C}$ and the coating time was measured from this point. The rotor speed was then gradually increased to $3000 \mathrm{rev} \mathrm{min}^{-1}$, and the coating continued for $40 \mathrm{~min}$. Time and temperature data were collected and the specimens were removed at required intervals for analysis. Monolayer coatings of the fillers were used. It has been shown previously $3,5,6$ that monolayer coatings corresponded to $6.0 \mathrm{wt}-\%$ of stearic acid on the magnesium hydroxide, and 4.0 at- $\%$ stearic acid on the calcium carbonate used here. Equivalent weights of the metal stearates were calculated and the percentages by weight and specimen designations are given in Tables 2 and 3.

Table 1 Technical data for coating agents

\begin{tabular}{lllll}
\hline & Mg stearate & Ca stearate & Zn stearate & Stearic acid \\
\hline Formula & {$\left[\mathrm{CH}_{3}\left(\mathrm{CH}_{2}\right)_{16} \mathrm{COO}_{2} \mathrm{Mg}\right.$} & {$\left[\mathrm{CH}_{3}\left(\mathrm{CH}_{2}\right)_{16} \mathrm{COO}_{2} \mathrm{Ca}\right.$} & {$\left[\mathrm{CH}_{3}\left(\mathrm{CH}_{2}\right)_{16} \mathrm{COO}_{2} \mathrm{Zn}\right.$} & $\mathrm{CH}_{3}\left(\mathrm{CH}_{2}\right)_{16} \mathrm{COOH}$ \\
Relative molar mass & $590 \cdot 3$ & $606 \cdot 1$ & $631 \cdot 4$ & $284 \cdot 0$ \\
Literature melting temperature, ${ }^{\circ} \mathrm{C}$ & $132($ Ref. 8) & $150-154$ (Ref. 8) & 130 (Ref. 8) & $69 \cdot 6$ (Ref. 9) \\
DSC melting temperature, ${ }^{\circ} \mathrm{C}$ & 94,125 & 137 & 131 & 67 \\
\hline
\end{tabular}




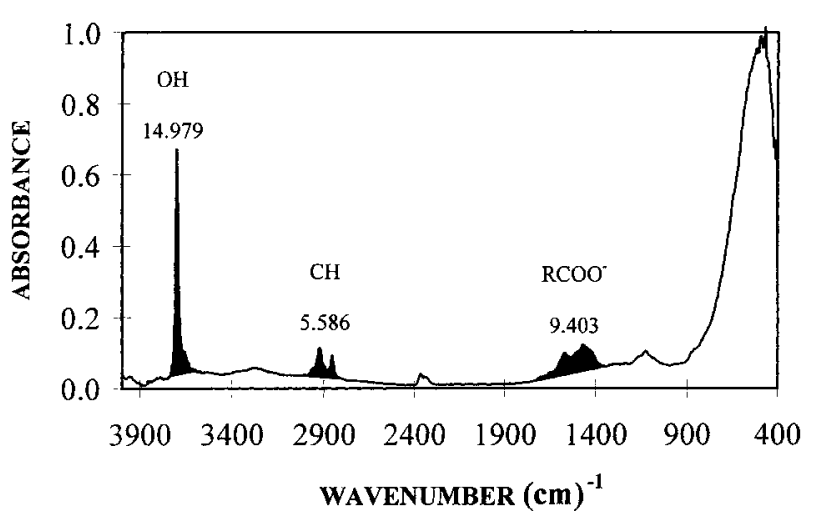

1 Diffuse reflectance Fourier transform infrared spectrum of magnesium hydroxide coated with $6.2 \mathrm{wt} \%$ magnesium stearate after $\mathbf{4 0}$ min mixing

\section{ANALYSIS}

Specimens were removed after various intervals, and analysed by FTIR and thermal analysis. The coated fillers were also examined by wide angle X-ray diffraction (XRD) and by X-ray photoelectron spectroscopy (XPS).

Analysis by FTIR was carried out using a quantitative diffuse reflectance FTIR (DRIFT) method developed earlier. ${ }^{9}$ Some of the filler $(2.5 \mathrm{wt}-\%)$ was dispersed in spectroscopic grade $\mathrm{KBr}$. A sample of this diluted filler was placed in the stainless steel cup of a DRIFT attachment, and scanned using a Unicam Mattson 3000 spectrometer from 4000 to $400 \mathrm{~cm}^{-1}$. Using a resolution of $4.00 \mathrm{~cm}^{-1}$ and a speed of $0.6 \mathrm{~cm} \mathrm{~s}^{-1}, 400$ scans were accumulated. Pure $\mathrm{KBr}$ was used to provide a background reading. Specimens of coatings and coated fillers were examined by heating from 30 to $180^{\circ} \mathrm{C}$ using a DuPont Thermal Analyser Model 2000 fitted with a DSC cell. Temperatures and enthalpies of melting and crystallisation were recorded.

Wide angle XRD traces were obtained in the reflection mode, using a Philips type PW diffractometer with $\mathrm{Cu} \mathrm{K}$ radiation, and a graphite monochromator to remove the $\mathrm{K}_{\beta}$ radiation. Traces were recorded for values of $2 \theta$ from 19 to $24^{\circ}$.

Measurements by XPS were made using a VG Escalab Mark 1 spectrometer. Quantification by XPS was achieved by measurement of peak areas after subtraction of a Shirley type background, with appropriate corrections also being made for photoelectron cross-sections, inelastic mean free

Table 2 Surface compositions of magnesium hydoxide based fillers

\begin{tabular}{|c|c|c|c|c|c|c|}
\hline \multirow[b]{2}{*}{ Code } & \multirow[b]{2}{*}{ Surface material } & \multicolumn{5}{|c|}{$\begin{array}{l}\text { Composition, at.-\% } \\
\text { (excluding H) }\end{array}$} \\
\hline & & C & 0 & $\mathrm{Mg}$ & $\mathrm{Zn}$ & $\mathrm{C} / \mathrm{Mg}$ \\
\hline & Magnesium hydroxide only & $8 \cdot 1$ & $51 \cdot 4$ & $40 \cdot 5$ & $\ldots$ & $0 \cdot 2$ \\
\hline MMSC & With 6.2 wt-\% Mg stearate & $37 \cdot 8$ & $31 \cdot 0$ & $31 \cdot 1$ & $\ldots$ & $1 \cdot 2$ \\
\hline MCSC & With 6.4 wt-\% Ca stearate & $30 \cdot 9$ & 33.8 & $35 \cdot 3$ & $\ldots$ & 0.9 \\
\hline MZSC & With 6.7 wt- $\%$ Zn stearate & $49 \cdot 1$ & $25 \cdot 5$ & $25 \cdot 3$ & $0 \cdot 2$ & 1.9 \\
\hline MSAC & With 6.0 wt-\% stearic acid & $36 \cdot 1$ & $32 \cdot 0$ & 31.9 & $\ldots$ & $1 \cdot 1$ \\
\hline
\end{tabular}
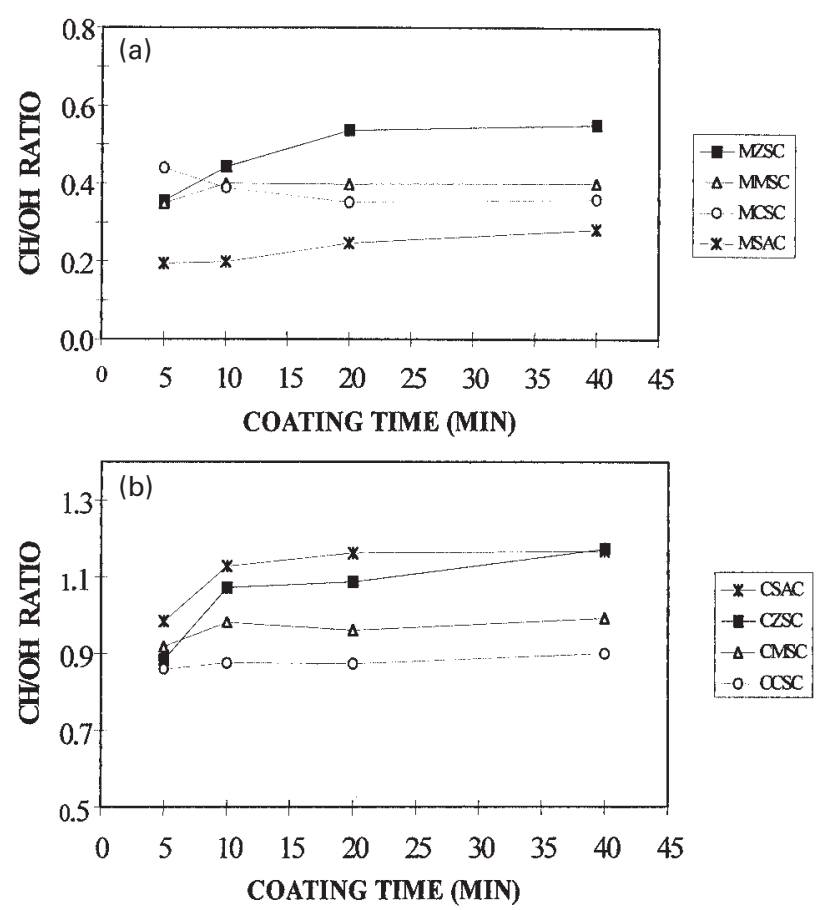

2 a $\mathrm{CH} / \mathrm{OH}$ ratio for magnesium hydroxide and $b \mathrm{CH} / \mathrm{CO}$ ratio for calcium carbonate $v$. time with various coatings from DRIFT data: for explanations of designation abbreviations see Tables 2 and 3

paths, energy analyser transmission, and angular asymmetry in photoemission when required.

\section{Results}

A typical spectrum for magnesium hydroxide coated with magnesium stearate, with major peaks and relative areas identified, is shown in Fig. 1. Quantitative measurements were carried out using integrated areas under the $\mathrm{CH}$ stretching band at $3001-2785 \mathrm{~cm}^{-1}$, the $\mathrm{OH}$ stretching band at $3751-3605 \mathrm{~cm}^{-1}$ for magnesium hydroxide, and the $\mathrm{CO}$ bending vibration at $2700-2395 \mathrm{~cm}^{-1}$ for calcium carbonate. Calculations of the $\mathrm{CH} / \mathrm{OH}$ and $\mathrm{CH} / \mathrm{CO}$ ratios were carried out for magnesium hydroxide and calcium carbonate respectively. The results are shown in Fig. $2 a$ and $b$. The first measurements were made after $5 \mathrm{~min}$, since the coating was added at zero mixing time and was not even uniformly mixed after a short period. It is known that ${ }^{10}$ the stearate only becomes detectable by this technique when coating has occurred.

The reactions were investigated further using differential thermal analysis. Calcium and zinc stearate and stearic acid all produced single, albeit rather broad melting peaks with maxima at 136,131 , and $67^{\circ} \mathrm{C}$ respectively, while for magnesium stearate a major peak was observed at $125^{\circ} \mathrm{C}$, with a minor peak at $94^{\circ} \mathrm{C}$ (Fig. 3). Table 1 shows that there are differences between these values, and those reported in

Table 3 Surface compositions of calcium carbonate based fillers

\begin{tabular}{|c|c|c|c|c|c|c|c|c|}
\hline \multirow[b]{2}{*}{ Code } & \multirow[b]{2}{*}{ Surface material } & \multicolumn{7}{|c|}{ Composition, at.-\% (excluding $\mathrm{H}$ ) } \\
\hline & & C & $\mathrm{O}$ & $\mathrm{Ca}$ & $\mathrm{Mg}$ & $\mathrm{Zn}$ & $\mathrm{C} / \mathrm{Ca}$ & $\mathrm{CH} / \mathrm{CO}_{3}$ \\
\hline & Calcium carbonate only & $26 \cdot 9$ & $51 \cdot 3$ & $21 \cdot 7$ & $\ldots$ & $\ldots$ & $1 \cdot 2$ & $0 \cdot 3$ \\
\hline CMSC & With $4.2 \mathrm{wt}-\% \mathrm{Mg}$ stearate & $49 \cdot 3$ & $35 \cdot 3$ & $15 \cdot 4$ & $\ldots$ & $\ldots$ & $3 \cdot 2$ & $2 \cdot 4$ \\
\hline CCSC & With 4.3 wt- $\%$ Ca stearate & $43 \cdot 3$ & $40 \cdot 3$ & $16 \cdot 4$ & $\ldots$ & $\ldots$ & $2 \cdot 6$ & $1 \cdot 7$ \\
\hline CSZC & With 4.5 wt- $\%$ Zn stearate & $58 \cdot 8$ & $29 \cdot 0$ & 11.5 & $\ldots$ & 0.7 & $5 \cdot 1$ & $4 \cdot 4$ \\
\hline CSAC & With 4.0 wt- $\%$ stearic acid & $60 \cdot 6$ & $27 \cdot 3$ & $12 \cdot 1$ & $\ldots$ & $\ldots$ & $5 \cdot 0$ & $4 \cdot 6$ \\
\hline
\end{tabular}




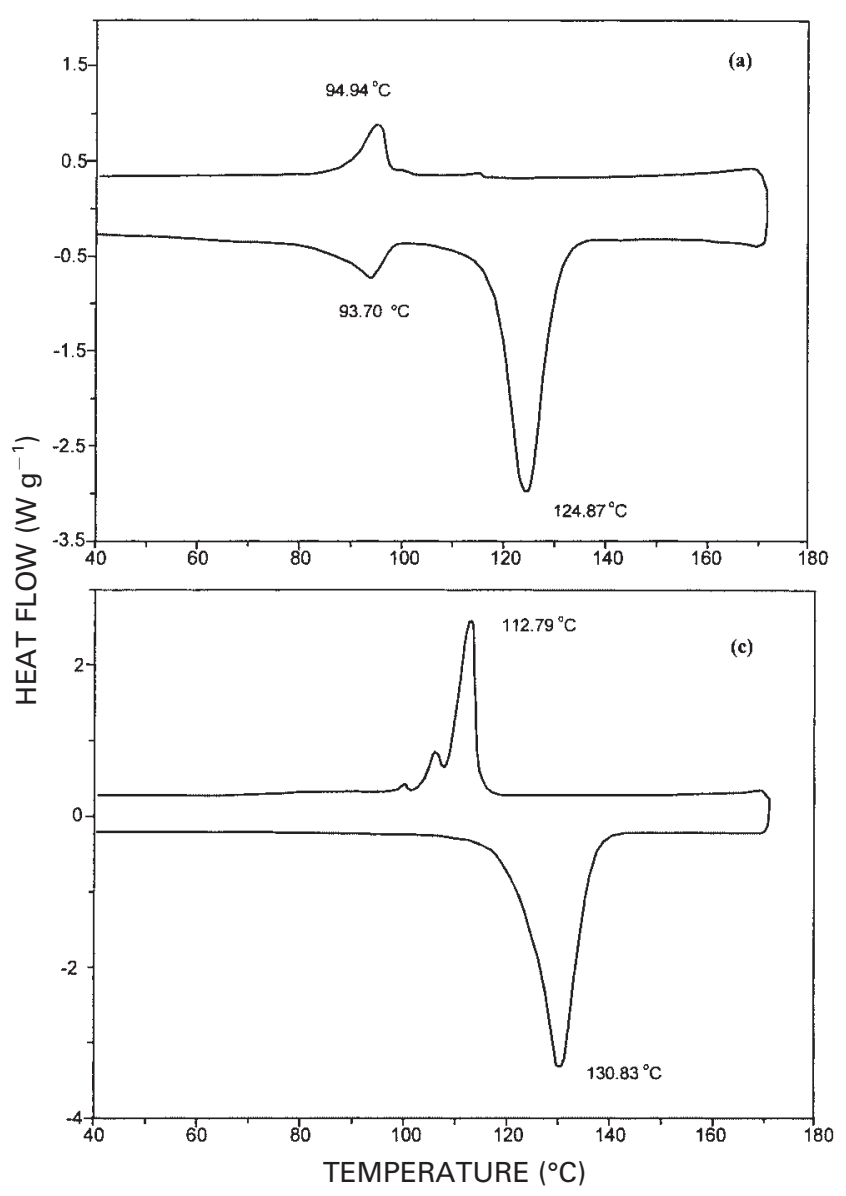

$a \mathrm{Mg}$ stearate; $b$ Ca stearate; $c \mathrm{Zn}$ stearate; $d$ stearic acid

3 Differential scanning calorimetry traces for different coatings

the literature. Markley ${ }^{10}$ states that 'The data reported in the literature with respect to the melting points of the metallic soaps leave much to be desired in the way of concordance'. This is partly because of the difficulty of preparing highly pure neutral metallic salts; DSC traces clearly indicate that this is the situation with the specimens examined in this paper. Not only are the melting peaks broad, and two are observed for magnesium stearate (the lower one possibly owing to acid salt), but on cooling calcium stearate and stearic acid crystallise as might be expected, while zinc stearate produces a multiple crystallisation peak and magne-

sium stearate only a small crystallisation peak at $95^{\circ} \mathrm{C}$. Polymorphism is also a well known phenomenon for fatty acids, and their salts and has been observed for alkaline earth salts but generally becomes simpler with increasing atomic weight of the metal, ${ }^{11}$ as observed in this paper.

When coating is carried out, the coating and filler are heated up to $140^{\circ} \mathrm{C}$, and the coating can undergo a number of possible changes. These are as follows:

(i) melting and recrystallisation, independent of filler (it is possible that calcium stearate may not melt fully at this temperature)

(ii) melting and coating on to the filler without recrystallisation

(iii) melting and coating on to the filler with recrystallisation and/or transformation to a different phase

(iv) melting and reacting with the filler.

It is possible of course that any combination of these possibilities may occur. In order to investigate what was actually occurring, peak areas were related to those for $100 \%$ of the component concerned and corrected for the amount of coating actually present (see the Appendix for
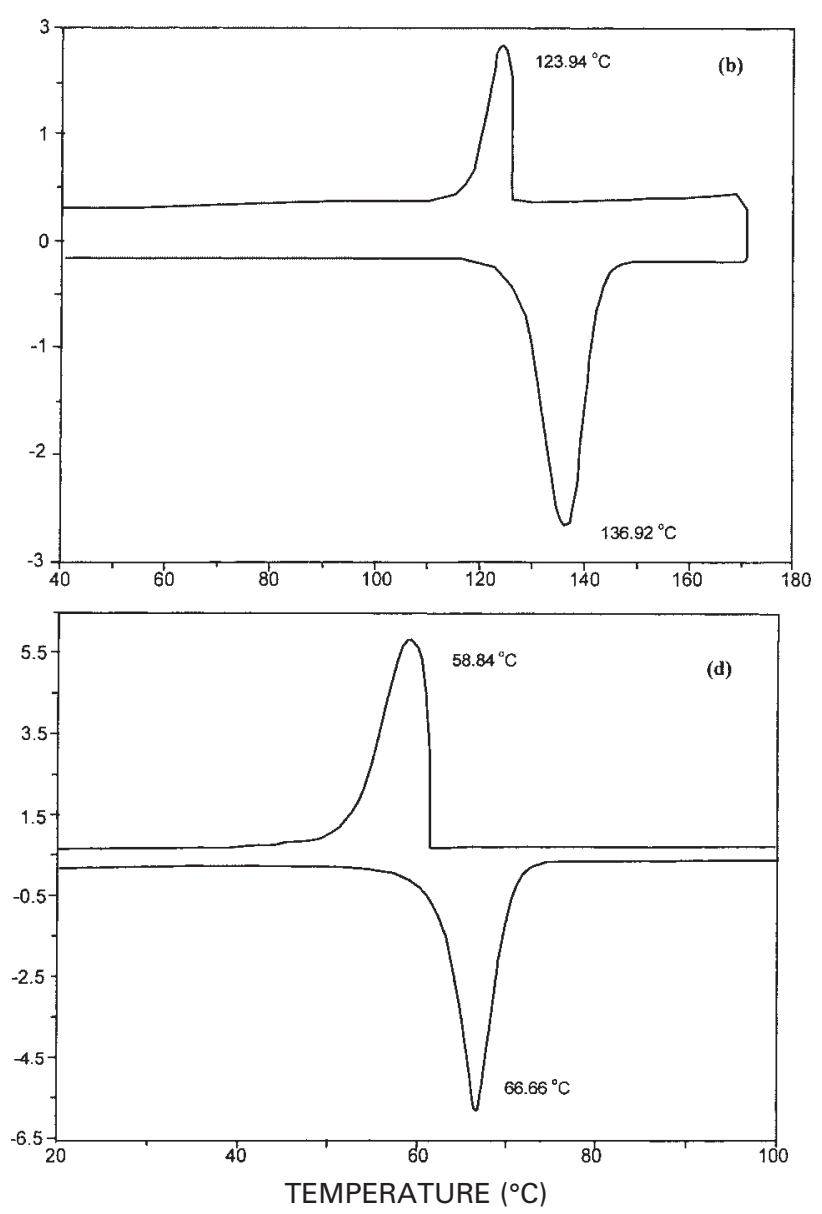

specimen calculation). Figure 4 shows how the fraction of calcium stearate decreases as the temperature increases for specimens coated in a Waring (bench scale) mixer, using different heater voltages. When calcium stearate is heated, and immediately cooled in a DSC cell (Fig. 3b), the amount of crystallisation corresponds to $\sim 71 \%$ of that originally present. This approximates to the amount of coating detected at low heater voltages. However, as temperature in the Waring increases, the proportion of free component decreases, and the most dramatic decrease occurs when the melting temperature of calcium stearate is reached. It is suggested that in this case, (ii) above is observed.

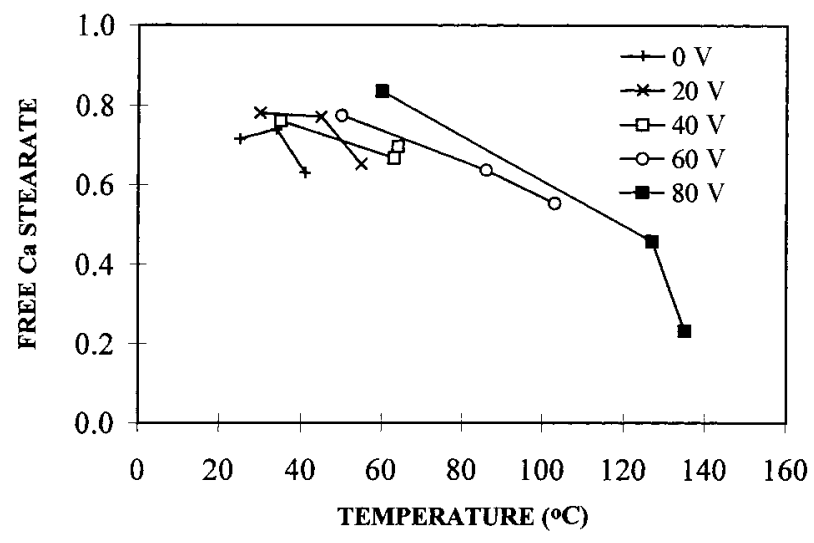

4 Free calcium stearate (CS) against temperature for 6.4 wt-\%CS coated magnesium hydroxide from DSC results 

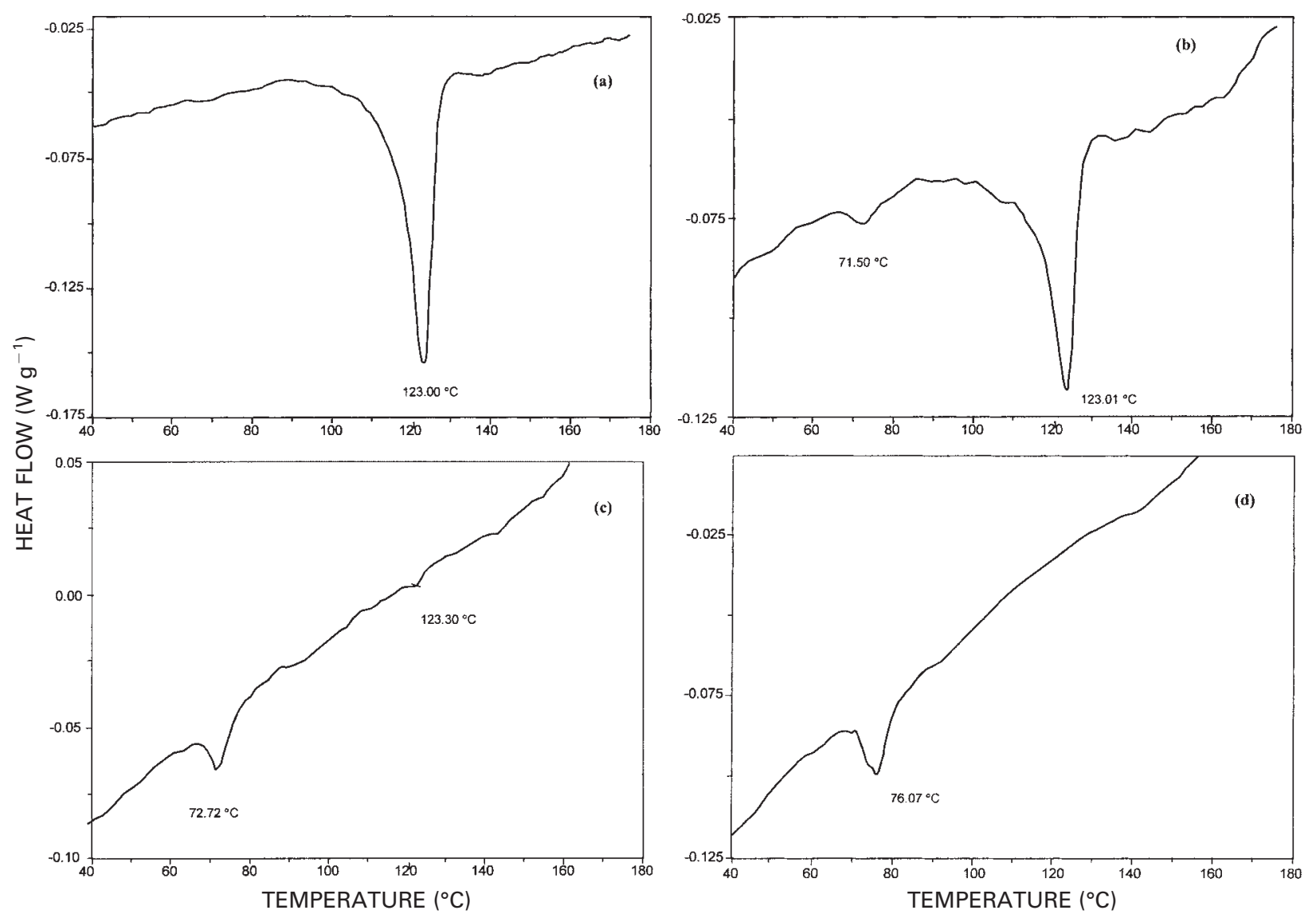

a $5 \mathrm{~min}$; $b 10 \mathrm{~min}$; c $20 \mathrm{~min}$; $d 40 \mathrm{~min}$

5 Differential scanning calorimetry traces for magnesium hydroxide coated with zinc stearate for different coating times

When changes during coating are monitored by thermal analysis, distinct melting peaks are observed in the regions $60-80,80-110$ or $110-140^{\circ} \mathrm{C}$. These are designated arbitrarily be denoted A, B, or C forms, respectively. Similar observations have been made by Gallay and Puddington for sodium stearate and peaks attributed to unidimensional melting, melting in a second dimension at right angles to the molecular axis, and completion of the bidemsional melting of the axis. ${ }^{12} \mathrm{~A}$ number of other authors have referred to the presence of polymorphic crystalline forms in metal soaps. ${ }^{11,13-15}$ Figure 5 shows the series of changes in melting behaviour when magnesium hydroxide is coated with zinc stearate using the Fielder mixer. Figures 6 and 7 summarise the observed changes in concentration of crystalline compounds when magnesium hydroxide and calcium carbonate are coated with stearates and stearic acid, also in the Fielder. The observed melting temperatures are given in Table 4 . These results illustrate the complexity of the coating process. Clearly the systems studied act in various ways, depending on both the coating and the filler.

Coated fillers were also examined by XPS. Surface composition results are given in Tables 2 and 3. The ratio $\mathrm{C} / \mathrm{Mg}$ reflects the amount of organic material on the surface of the magnesium hydroxide, and ratios $\mathrm{C} / \mathrm{Ca}$ and $\mathrm{CH} / \mathrm{CO}_{3}$ reflect the total surface carbon and the organic carbon on calcium carbonate. Results suggest that zinc stearate produces the most effective coating. Stearic acid is also particularly good for calcium carbonate.

Wide angle XRD traces for magnesium hydroxide coated with magnesium stearate in the Fielder as a function of coating time are shown in Fig. 8. It is seen that although there is a broad peak at a $2 \theta$ value of $\sim 21^{\circ}$, diffraction peaks owing to magnesium stearate are not detectable, even after a coating time of $5 \mathrm{~min}$. A comparison with a trace for magnesium hydroxide mixed with the same amount of magnesium stearate (Fig. 9) shows that crystalline magnesium stearate has disappeared during coating.

\section{Discussion}

It is seen from DRIFT results in Figs. 2 and 3 that stearic acid is the most effective coating agent for calcium carbonate, but the least effective for magnesium hydroxide. For both fillers, the amounts of stearate detected decreases as follows

$$
\mathrm{Zn}>\mathrm{Mg}>\mathrm{Ca}
$$

Previous infra red results have shown that stearic acid reacts fully with magnesium hydroxide. ${ }^{10}$ Thermal analysis shows a small peak with a maximum at $76^{\circ} \mathrm{C}$ after 40 min coating. It is suggested that this is because of a polymorph of magnesium stearate, rather than residual stearic acid. When calcium carbonate is coated with stearic acid free and possibly increasing amounts of stearate are produced during coating, but as seen by DRIFT analysis, ${ }^{10}$ residual stearic acid is still present after 40 min coating. For both fillers with stearic acid, the coating process is of type (iv) above. When metal stearates are used, thermal analysis shows that the disappearance of stearates in their original crystalline form is observed in all cases together with some formation of lower melting polymorphs. Calcium stearate disappears at the slowest rate, particularly in conjunction with magnesium hydroxide. Magnesium stearate disappears more slowly than zinc stearate with magnesium hydroxide; when the filler is calcium carbonate, the reverse is true. 

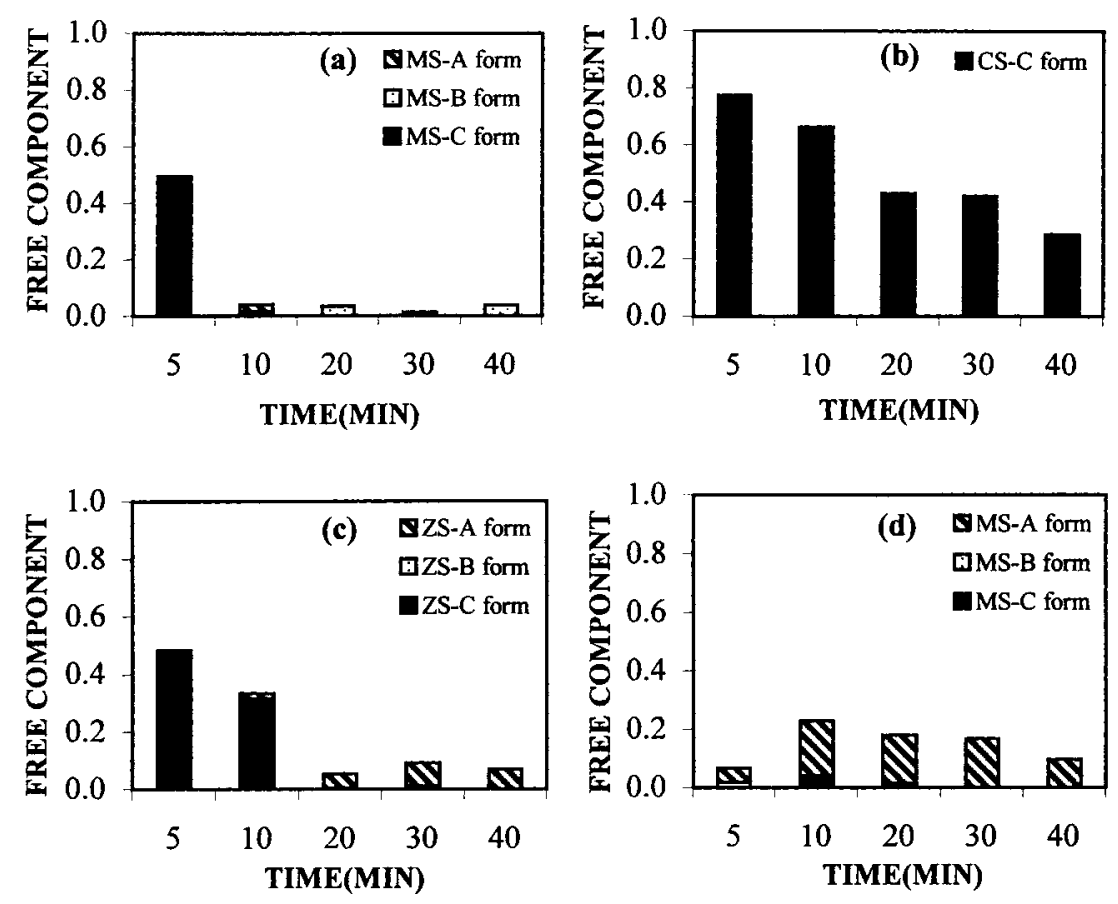

$a \mathrm{Mg}$ stearate; $b$ Ca stearate; $c \mathrm{Zn}$ stearate; $d$ stearic acid

6 Free component $v$. coating time for magnesium hydroxide with different coatings: MS Mg stearate, CS Ca stearate, ZS Zn stearate; for details of $A$, B, and C forms see text

Taken together, results for calcium stearate coating suggest that a type (ii) process is occurring. Traces detected by DSC for magnesium and zinc stearates (Fig. $3 a$ and $c$ ) show that even when heated alone, recrystallisation is more complex. For magnesium stearate $\sim 30 \%$ of the original crystalline material is produced, only in B form. Coating of both fillers proceeds via a type (iv) process, with only very small amounts of low melting material remaining. On recrystallisation $\sim 80 \%$ of the original crystalline zinc stearate is produced, with the process occurring over a range of temperatures. Figures 6 and 7 show that again small amounts of low melting material are produced during coating, corresponding to a type (iii) process, although in the case of calcium stearate, these disappear after a coating time of $20 \mathrm{~min}$. Results suggest that coating occurs more readily when rapid recrystallisation of the high melting form of the stearate does not occur, distinguishing the behaviour of magnesium and zinc stearates from calcium stearate.
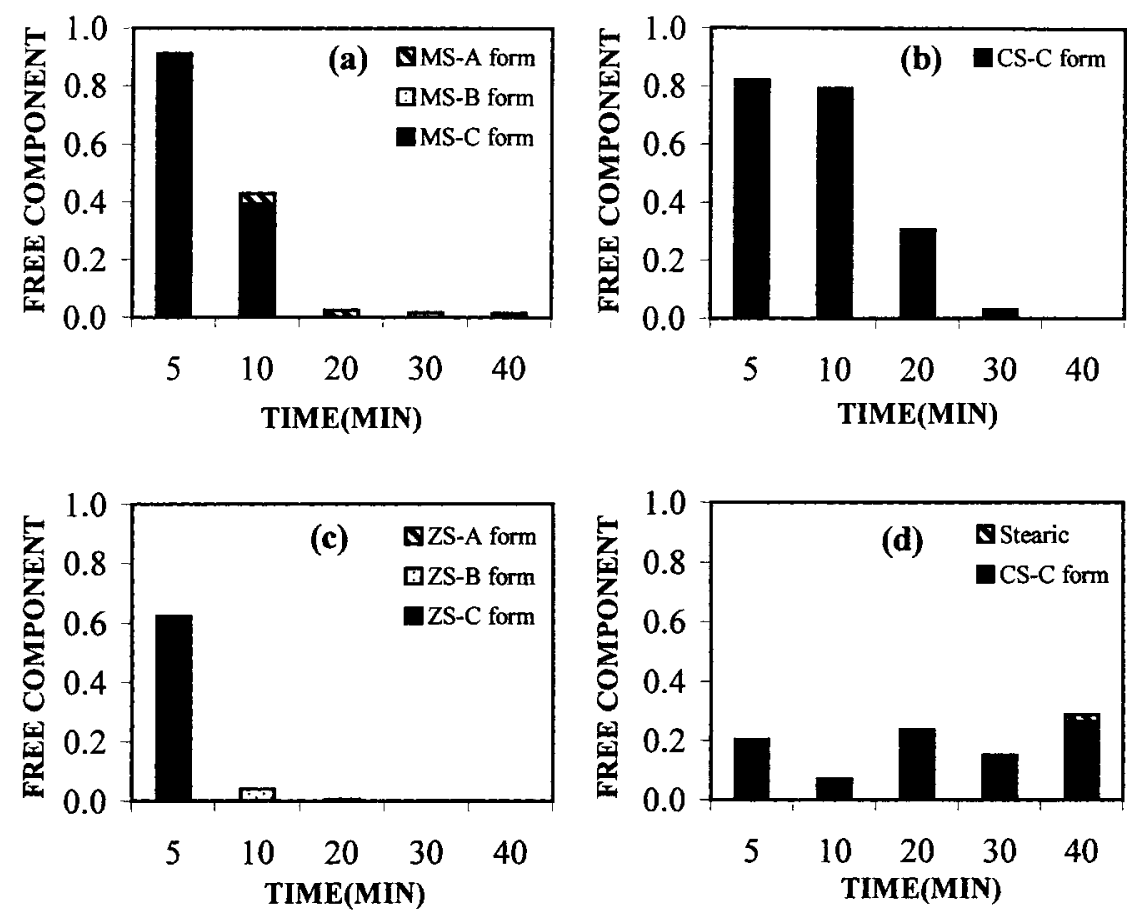

a Mg stearate; $b$ Ca stearate; $c$ Zn stearate; $d$ stearic acid

7 Free component versus coating time for calcium carbonate with different coatings: MS Mg stearate, CS Ca stearate, ZS Zn stearate, Stearic - stearic acid; for details of A, B, and C forms see text 


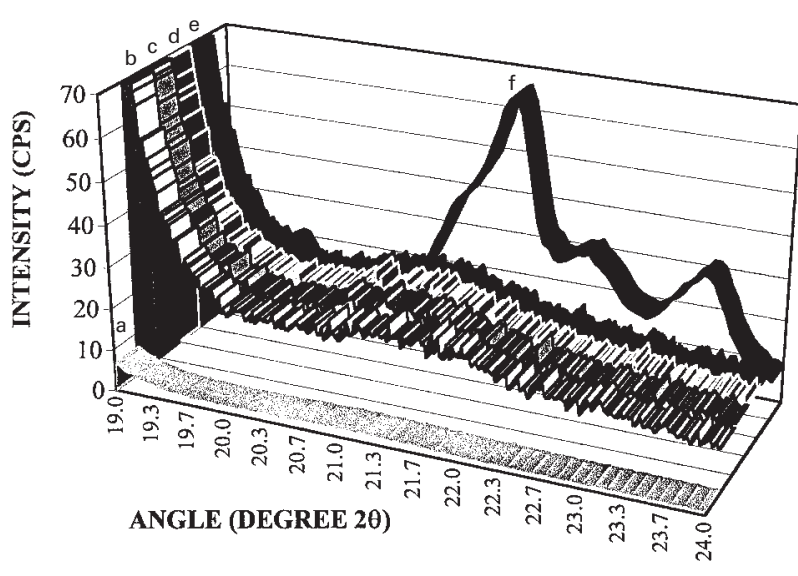

a MHUC; $b$ MMSC2605; $c$ MMSC2610; $d$ MMSC6220; $e$ MMSC6240; $f$ MgSt

8 X-ray diffraction traces of magnesium hydroxide uncoated (MHUC), and coated (MMSC) with $6.2 \% \mathrm{mag}$ nesium stearate after $5,10,20$, and 40 min coating time: MgSt magnesium stearate

Information about the coating on the filler surface is provided by XPS. Some organic carbon is detected on the uncoated fillers, probably owing to compounds used during filler production. This has been observed previously. ${ }^{9}$ As expected, the amount of organic carbon increases significantly in the presence of coatings. The amount of organic carbon is very high when calcium carbonate is coated with stearic acid, but relatively low with magnesium hydroxide, consistent with the DRIFT results. Of the metal stearates, the amount of organic carbon detected is lowest with calcium stearate, particularly for calcium carbonate. This data relates well with both the DRIFT, and thermal analysis results, which show that unreacted calcium stearate is present at the end of coating. The high level of organic carbon observed on calcium carbonate when zinc stearate is used is again consistent with its disappearance during coating. (It is also seen that zinc itself can be detected; zinc is detectable by XPS at lower levels than $\mathrm{Ca}$ or $\mathrm{Mg}$.)

Changes during coating could also be detected by XRD For example, when magnesium hydroxide is coated with magnesium stearate diffraction peaks for magnesium stearate are not detectable, even after a coating time of 5 min (Fig. 8). However, when zinc stearate was used as a coating, distinct diffraction peaks owing to zinc stearate were detected after coating times of 5 and $10 \mathrm{~min}$. However the peak then disappeared, consistent with the therma analysis results (Fig. 6c). When stearate peaks disappear, they are replaced by a single broad peak owing to the coating, corresponding to a $d$ spacing of $0.41 \mathrm{~nm}$. This peak is typical of an amorphous halo, indicating that there is some degree of order resulting from the close packing of near neighbours.

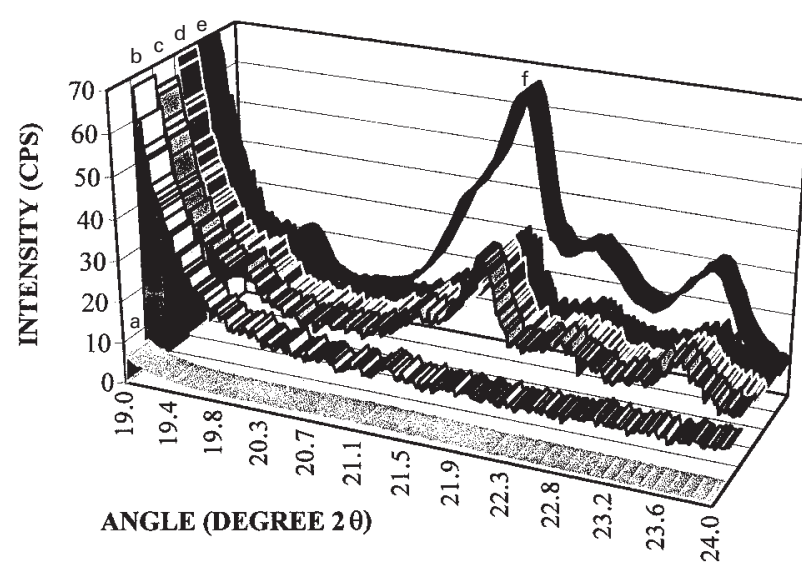

a MHUC; $b$ MMSC2605; $c$ MMSC2610; $d$ MMSC6220; $e$ MMSC6240; $f$ MgSt

9 X-ray diffraction traces of magnesium hydroxide uncoated (MHUC), and mixed with $6.2 \%$ magnesium stearate (MMSA), after 5, 10, 20, and 40 min mixing time: MgSt magnesium stearate

\section{Conclusions}

When the dry coating process is used, complex changes occur. Stearic acid will react to produce stearate, while stearates melt and form coatings, but in some cases also form polymorphic metal stearates. Detailed analysis of coated fillers and the coating process can be carried out by the combined use of thermal analysis, diffuse reflectance Fourier transform infrared spectroscopy, and X-ray photoelectron spectroscopy. These three techniques serve to produce complementary information. Stearic acid produces the best coverage on calcium carbonate, but the poorest on magnesium hydroxide. Of the metal stearates, the best filler coverage is produced when zinc stearate is used, while calcium stearate produces the poorest coating. The reasons for this are partly attributable to the recrystallisation behaviour of the stearates, but are also filler dependent.

\section{Appendix}

\section{Calculation of unreacted coating}

A magnesium hydroxide filler coated for $5 \mathrm{~min}$ with $6.2 \mathrm{wt}-\%$ magnesium stearate showed a DSC peak at $122^{\circ} \mathrm{C}$ with a heat of fusion of $4.31 \mathrm{~J} \mathrm{~g} \mathrm{~g}^{-1}$, attributed to the $\mathrm{C}$ form of magnesium stearate. The heat of fusion for magnesium stearate alone was $140 \cdot 1 \mathrm{~J} \mathrm{~g}^{-1}$. Therefore the

Table 4 Temperatures of observed melting peaks, ${ }^{\circ} \mathrm{C}$

\begin{tabular}{|c|c|c|c|c|c|}
\hline \multirow[b]{2}{*}{ Surface material } & \multicolumn{5}{|c|}{ Coating time, $\min$} \\
\hline & 5 & 10 & 20 & 40 & 50 \\
\hline Magnesium hydroxide with 6.2 wt- $\%$ Mg stearate & 95,121 & 66,120 & 84 & 61 & 76 \\
\hline Magnesium hydroxide with 6.4 wt-\% Ca stearate & 120 & 120 & 122 & 122 & 122 \\
\hline Magnesium hydroxide with 6.7 wt-\% Zn stearate & 123 & 71,123 & 73,123 & 66,82 & 76 \\
\hline Magnesium hydroxide with 6.0 wt- $\%$ stearic acid & 78,98 & 65,124 & 70,126 & 66 & 76 \\
\hline Calcium carbonate with $4 \cdot 2$ wt- $\% \mathrm{Mg}$ stearate & 94,121 & 66,123 & 66 & 88 & 101 \\
\hline Calcium carbonate with 4.3 wt- $\%$ Ca stearate & 120 & 120 & 118 & 120 & Small residual peak \\
\hline Calcium carbonate with 4.5 wt- $\%$ Zn stearate & 123 & 106 & 71 & Small residual peak & Small residual peak \\
\hline Calcium carbonate with 4.0 wt- $\%$ stearic acid & $67,90 / 108 / 120$ & 114 & 65,112 & 114 & $66,113 / 124 / 132$ \\
\hline
\end{tabular}


weight fraction of unreacted $\mathrm{C}$ form $=(4.31 \times 100) /$ $(140 \cdot 21 \times 6 \cdot 2)=0.496$.

\section{References}

1. M. HANCOCK: in 'Particulate filled polymer composites', (ed R. N. Rothon), Chap. 8; 1995, Harlow, Longman Scientific and Technical.

2. R. N. ROTHON: in 'Particulate filled polymer composites', (ed R. N. Rothon), Chap. 4; 1995, Harlow, Longman Scientific and Technical.

3. C. L. RAYMOND: PhD Thesis, Loughborough University, UK, 1997.

4. P. R. HORNSBY and C. L. WATSON: J. Mater. Sci., 1995, 30, $5347-$ 5355.

5. B. HAWORTH and C. L. RAYMOND: Proc. Conf. on 'Eurofillers', Villeurbanne, France, 1997, British Plastics Federation, $251-254$.
6. M. Gilbert and P. Petiraksakul: Polym. Polym. Compos., $1997,5,535-539$.

7. M. GILBERT, P. PETIRAKSAKUL, and I. MATHESION: Proc. Conf. on 'Eurofillers', Villeurbanne, France, September 1999, 18.

8. K. S. MARKLEY: in 'Fatty acids', (ed. K. S. Markley), Part 2, $744-747$; 1961, New York, Interscience.

9. M. GILBERT, I. SUTHERLAND, and A. GUEST: J. Mater. Sci., 2000, 35, $2115-2120$

10. K. S. MARKLEY: in 'Fatty acids', (ed. K. S. Markley), Part 1, 234; 1960, New York, NY, Interscience.

11. J. H. M. REK: in 'Differential thermal analysis', (ed. R. C. Mackenzie), vol. 2, Chap. 43, 484; 1972, London, Academic Press.

12. W. GALLAY and I. E. PUDDINGTON: Can. J. Res., 1943, 21, $202-210$.

13. G. S. HATTIANGDi, M. J. VOLD, and R. A. volD: Ind. Eng. Chem., 1949, 41, 2320.

14. F. H. FERGUSON, F. B. RoSevar, and R. C. Stillman: Ind. Eng. Chem., 1943, 35, 1005-1012.

15. F. H. Ferguson, F. B. ROSEVAR, and H. NORDSieck: J. Am. Chem. Soc., 1947, 69, 141-146. 